\title{
Psychological preparation of the 2004 South African Olympic team
}

\author{
Clinton Gahwiler (BA Hons, MA) \\ Sport Science Institute of South Africa, Newlands, Cape Town
}

\begin{abstract}
Background. The 2004 Athens Olympics represented the greatest opportunity for psychological preparation yet afforded a multicode South African team. A coordinating psychologist was appointed a year before the event, with access to financial and other resources.
\end{abstract}

Aim. The purposes of this paper are fourfold: (i) to describe a 5-stage model used for the psychological preparation of the 2004 South African Olympic team; (ii) to report on the athletes and their management teams' perceptions of its efficacy; (iii) to describe the perceived positive and negative determinants of these same subjects' state of mind at the Olympics; and (iv) to make recommendations for the existing model's further improvement.

Results. The psychological preparation was well received, with almost all athletes and coaches requesting an expansion thereof in the future. Recommendations are made for the model's improvement, particularly for its ongoing implementation throughout the 4-year Olympic cycle.

\section{Introduction}

Since the early 1980s it has become increasingly common to have psychologists forming a part of the various countries' medical teams to the Olympic Games. Australia has been one of the most proactive countries in this regard. Since Sydney 2000 the Australians have aspired to having one psychologist per sporting code. ${ }^{1}$ To date, South African multicode teams have on four occasions included a psychologist

\section{CORRESPONDENCE:}

Clinton Gahwiler

Unit 16

Sports Science Institute of South Africa

Boundary Road

Newlands

7700

Tel: 021-659-5655

Fax: 086-624-7988

E-mail: sportpsych@xsinet.co.za as part of their travelling teams. Two of these were to the AllAfrica Games (C Gahwiler in 1999, P Nel in 2003), and two to the Olympic Games (J Potgieter in 2000 and C Gahwiler in 2004).

Potgieter reported having 21 formal individual consultations and 3 team consultations at the Olympic Games in Sydney 2000 (unpublished manuscript, 2000). In his report he implies this to be a relatively low number of interventions, and cites the lack of opportunities (preOlympics) to establish rapport between psychologist and athletes as the main reason. Both Gahwiler (unpublished manuscript, 1999) and Nel (unpublished manuscript, 2003) found that coaches and athletes they had met with prior to the All-Africa Games were more likely to use their services during the actual event than athletes they had not consulted with before. This is also consistent with the experiences of non-South African psychologists, e.g. Bond in Australia ${ }^{1}$ and McCann in the USA. ${ }^{2}$ An opportunity to meet and develop rapport with travelling team members beforehand is therefore vital to maximising the use of sport psychology services at major events.

After the Sydney Olympics, Potgieter used a questionnaire to identify the athletes' perceptions of how well they had been prepared for the Games physically, technically and psychologically. Athletes felt least prepared psychologically, with only $66 \%$ of them reporting adequate preparation on this level. ${ }^{3}$ This is relatively low considering that the event is likely to have been at least one of, if not the most important in these athletes' careers. Potgieter recommended that in future provision be made for more extensive psychological preparation prior to the Olympics. ${ }^{3}$

One of the main difficulties in implementing this approach has been that in the past, the medical teams (including the psychologist) have usually been appointed at quite a late stage. The bulk of the psychological interventions have therefore only occurred at the actual event. Ideally, however, psychological preparation should be an ongoing, practical component of all training programmes, ${ }^{1}$ so that the psychologist's role at the actual event is purely one of crisis management and support.

Another aspect that has largely been ignored in the South African context, is that of psychological support after the event. Potgieter reported that $77 \%$ of the South African athletes experienced some feelings of depression after the 
Sydney Olympics. ${ }^{3}$ McCann has made similar observations over the course of his significant experience with US Olympic teams. $^{2}$ In a South African context, both Potgieter and Gahwiler have in the past recommended that opportunities for post-event support be made available to South African teams (unpublished manuscripts).

In light of past experiences, the challenge for the 2004 Olympics was to implement a more comprehensive psychological preparation programme, specifically allowing more time for developing rapport between psychologist and team members prior to the Games, and to provide opportunities for intervention after the Games.

This paper has four aims: (i) to provide a synopsis of the model employed for the psychological preparation of the South African Olympic team to Athens 2004; (ii) to report on the perceptions of athletes, team coaches and managers with regard to the efficacy of this model; (iii) to report on athletes' and management staffs' own descriptions of their state of mind at the Games, together with their perceptions of the main positive and negative influences in this regard; and (iv) to make recommendations for the ongoing improvement of a model for the psychological preparation of South African multicode teams.

\section{Methods}

A 5-phase model for the mental preparation of multicoded teams

The structured psychological preparation programme began a year before the 2004 Athens Olympics, with the appointment of a coordinating psychologist by the National Olympic Committee of South Africa (NOCSA). While the ideal would be to have an entire 4-year cycle of duty, electing a psychologist a year in advance certainly presented the opportunity for the most comprehensive psychological preparation programme yet of a multicoded South African team. One of the coordinator's first tasks was to establish a network of psychologists around the country who were able to (regionally) provide psychological services. In phase 1 of the model, these psychologists were invited to attend a 3-day workshop (see below) in order to ensure consistency of message.

\section{Phase 1: Introduction and individual assessments}

Athletes on NOCSA's 'Operation Excellence' programme were invited to attend the Pacific Institute's 3-day 'Investment in Excellence' workshop as an introduction to the psychological preparation. During the workshop each athlete also underwent an individual needs analysis with the coordinating psychologist. The aim of this assessment was to identify psychosocial areas, both within and outside of sport, in which the athlete might benefit from some form of psychosocial intervention. This dual focus is consistent with the common sport psychology principle of facilitating not only the performance of the 'athlete', but also the wellbeing of the 'total person'., The author's own experience suggests that it is impossible to maintain the former (i.e. performance) effectively on a sus- tainable basis without concurrently managing the latter (i.e. wellbeing).

\section{Phase 2: Intervention}

Based on the individual assessments, where appropriate, athletes were referred to a psychologist close to their home for the actual intervention. This not only ensured ease of access, but also some flexibility in allowing athletes to work with consultants with whom they felt most comfortable. There was ongoing contact between the regional and coordinating psychologists in order to ensure continuity and consistency of message.

\section{Phase 3: Monitoring and feedback}

The only opportunity the coordinating psychologist had personally to follow-up with team members spread around the country, was at the two pre-Olympic training camps, when athletes from all the codes were brought to a communal camp for the purposes of training and logistical preparations. The first was held 3 months before, and the second immediately prior to departure for Athens. These camps presented an opportunity for the coordinating psychologist to follow-up on athletes with whom an earlier needs analysis had been conducted, and also to meet with those who had not been seen before. During the second of these camps, the psychologist also addressed the entire South African team, which provided a valuable opportunity for an even broader exposure to the squad, including those members who still had not had any form of contact with the psychologist.

\section{Phase 4: Olympic Games}

The coordinating psychologist attended the Games as part of the 11-strong medical team. Psychological services were made available 24 hours a day. The psychologist's self-imposed mandate was to make himself as approachable as possible, without imposing. Efforts were also made to be as visible as possible (e.g. at meals, and by organising athletes' ice-baths), so as to increase the likelihood of being around at what has been described as a 'teachable moment' (Bond: personal communication), in which one has the opportunity to be particularly effective by being on-hand to say the right thing at the right time. In this report these spontaneous miniconsultations are referred to as 'unscheduled individual consultations'.

Aside from these obvious roles, the psychologist generally endeavoured to help out wherever appropriate, and also placed a daily inspirational 'thought for the day' in each of the athlete blocks.

\section{Phase 5: Post-Olympics}

For the first time, there was a budget for post-Olympic psychological intervention. The aim of this was (where needed) to support the re-integration of positive and negative Olympic experiences into the athletes' future lives and competitions. 
On returning to South Africa, the coordinating psychologist immediately wrote a letter to each of the athletes. There were three reasons for this letter: (i) to comment briefly on what they could expect to experience emotionally post-Olympics; (ii) to remind them of the post-Olympics psychological services available to them; and (iii) to provide them with some feedback of the psychology questionnaires. At the same time, a detailed report was sent to NOCSA on the overall psychology programme, with recommendations for the future.

\section{Feedback questionnaires}

Feedback questionnaires were handed out to South African athletes and their management teams over the last 2 days in Athens. These included both 'descriptive' questions around their mental state at the Olympics, and 'evaluative' questions around their perceptions of the efficacy of the current psychological preparation programme and how to improve on it. The distracted nature of the last few days in the Olympic village made it difficult to get questionnaires completed and returned. In total, 53 questionnaires were received, 45 of which were from athletes, and a further 8 from their coaches and managers. This represents a response rate of $65 \%$ among the athletes, and $24 \%$ among their coaches and managers.

\section{Results}

The feedback questionnaires provided information on the respondents' perceptions of the 5-phase model described above, as well as of their own state of mind and what influenced them. A synopsis is given below of the most common responses to selected items of the feedback questionnaire.

How well prepared were you psychologically? (Scored on a scale 1 - 7, where 1 = not at all well, 7 = extremely well)

Athlete responses: 5.3 (range 2 - 7)

Coach / manager responses: 5.3 (range 3 - 7)

\author{
What affected your state of mind positively? - athlete \\ responses \\ Having prepared well generally: 8 (18\%) \\ Psychological preparation / sport psychologist: 7 (16\%) \\ The occasion: 6 (13\%) \\ Good performances and results: $6(13 \%)$ \\ Support and efficiency of coach and manager: 5 (11\%) \\ Support of team mates: 5 (11\%) \\ Support of family and friends: 5 (11\%)
}

What affected your state of mind positively? - coach / manager responses

Positive attitudes of team and colleagues: $3(38 \%)$

Having prepared well generally: $3(38 \%)$

The occasion: 2 (25\%)

What affected your state of mind negatively? - athlete responses

Disappointing performances and results: $9(20 \%)$

Coach / manager issues: 5 (11\%)
Fellow team members: $4(9 \%)$

External distractions: $4(9 \%)$

What affected your state of mind negatively? - coach / manager responses

Lack of support from NOCSA staff: 3 (38\%)

Unrealistic expectations by athletes: 2 (25\%)

What was emotionally the most challenging thing for you? - athlete responses

Disappointing results: 7 (16\%)

Being away from home for so long: $5(11 \%)$

Miscellaneous external distractions: $5(11 \%)$

Pressure of expectations: 4 (9\%)

Standard of opposition / competition: 4 (9\%)

Enormity of the occasion: $4(9 \%)$

What was emotionally the most challenging thing for you? - coach / manager responses

Disappointing results: 2 (38\%)

How clear are you about what you will be focusing on over the next year or two? (Scored on a scale 1 - 5 ,

where 1 = not at all clear, 5 = very clear)

Athlete responses: 3.2 (range 1 - 5)

Coach / manager responses: 4.7 (range 4 - 5)

How can we further improve psychological services?

- athlete responses

Start the process earlier: $5(11 \%)$

The support was good: 4 (9\%)

Need more of it: $4(9 \%)$

Need continuity: 2 (4\%)

How can we further improve psychological services? - coach / manager responses

More continuity pre- and post-Olympics: 6 (75\%)

\section{Psychology consultations}

From the pre-departure camp in Pretoria, through to leaving Athens at the end of the Games, a total of 87 psychological consultations took place. These may be divided into four types:

- formal individual consultations $(N=30)$ in which meetings were scheduled at the athlete's request

- unscheduled individual consultations $(N=48)$ which occurred spontaneously at training venues, over meals, on buses, etc.

- formal team sessions $(N=5)$ in which the explicit focus was psychological in nature

- attendance at general team meetings (at coaches' request), with occasional psychological contributions $(N=4)$.

The most common themes of the combined formal and unscheduled individual athlete consultations were general psychological skills training $(N=20)$, pressure of expectations $(N=11)$, and issues with coach or manager $(N=10)$. 
The most common themes of the non-athlete individual consultations were feedback on particular athletes $(N=10)$, issues with SA team management / support staff $(N=6)$, and personal emotional support $(N=5)$.

The main theme of the team consultations was team dynamics $(N=3)$.

\section{Discussion}

\section{Phase 1 - introduction and individual assessments}

All but one of the athletes (who was writing exams at the time) found the 3-day workshop to be both valuable and enjoyable. From the perspective of the coordinating psychologist phase 1 enabled him to establish rapport with a large proportion of the athletes prior to the actual Games (including those with whom he was not working directly). This was a critical determinant of the effective use of psychological services at the Games. The importance of the workshop is supported by the relatively high number of psychological consultations proportionate to team size at the Athens Olympics. Having said this, another contributing factor may be that South African athletes and coaches in general are becoming more receptive to the importance of psychological preparation.

\section{Phase 2 - intervention}

The model of having one psychologist doing the initial assessment, and thereafter coordinating a national network of other (psychology) service providers, ensured both logistical ease as well as the benefits afforded by continuity.

\section{Phase 3 - monitoring and feedback}

Phase 3 presented a valuable opportunity to follow up on the initial assessments and to further develop relationships with the athletes. In future, this phase should ideally be extended by including more regular interactions between the coordinating psychologist and the regionally based athletes, management staff and psychologists. This would most easily be achieved by having the coordinating psychologist visit each region regularly (e.g. every 6 months during the 4-year Olympic cycle).

\section{Phase 4 - Olympic Games}

In the Olympic village, the psychologist was provided with a local cellular phone and all team managers were given the number of this phone. Unfortunately, due to space restrictions no central room was allocated for psychological consultations. The biggest challenge this presented was that it made the psychological services less visible. On a functional level, however, this was dealt with by using a TV lounge in a nearby residents' centre for most formal consultations. Other consultations were also (albeit somewhat less privately) held in the lounges of the psychologist's or the athletes' flats.

Despite the good response to the psychology programme, there were still some athletes who might well have benefited from psychological services prior to, and in Athens, but who chose not to use them. Judging by the feedback forms, there were many factors which negatively influenced the athletes' state of mind. The influence from these factors might have been minimised or at least better managed with some (or in some cases further) psychological intervention. It is the author's opinion that further growing the scope of the preOlympic interventions would be a positive development.

The high demand of psychological skills training in the individual consultations also suggests that athletes should be exposed to this aspect long before actual events. Even though this intervention was the most comprehensive to date, there is still a long way to go before a system is in place which by default includes mental training on an ongoing basis.

Only a tiny minority (perhaps 2 or 3 athletes) actively resisted any form of psychological support. Interestingly, these exceptions tended to be athletes whose coaches were cynical about the role of psychology. This underlines the importance of coaches' education and involvement in the psychological processes prior to the Games.

The Athens Olympics reinforced this author's opinion that coaches and managers appear to be at particularly high risk of burnout at such events. Because their attitudes, moods and behaviours have both a direct and indirect impact on the athletes, it is crucial that they get the appropriate support prior to and also at the multicode event. In future Olympic cycles, more attention should be paid to preparing coaches and managers psychologically in the build-up to the Games.

In Athens the psychologist dealt with a surprising number of issues relating to the athlete-coach relationship. In almost all such cases the issues could easily have been prevented if the athlete and coach had had more time to build a trusting relationship. Most often these cases occurred where individual athletes had been assigned a coach with whom they had never worked with before. The upshot of this is that coach and athlete end up dealing with (normal) relationship-building crises in the cauldron of the Olympic Games. In other words, at probably the single most important event of their lives they had to deal with issues which really should have been sorted out years before. In light of the high-pressured context these issues were (not surprisingly) amplified in intensity. It is strongly recommended that this should not be allowed to happen again. Assuming that the wellbeing and performance of athletes is the main focus, then on selection of the athlete, appointment of support staff that $s /$ he is comfortable with should become an absolute priority. Cases in which this is not possible should be handled in a very sensitive manner by administrators, and also be added to the 'to do' list of the psychologists well in advance of the actual Games.

Based on the author's observations, the pressure of expectations remains one of the most significant limiting factors to performance. Besides having access to psychological intervention, the athletes' exposure to comments about competition outcomes (e.g. expected medal count) should 
also be limited as far as possible. There did seem to be a greater awareness of this compared with the build-up to the Sydney Games in 2000. However, it remains an area that needs more specific and consistent attention. Psychologists have a potentially important role in educating politicians, administrators and other non-competing team members on how to motivate and inspire in a way that does not create unnecessary pressure.

In theory the quieter time towards the end of the Olympic Games is an ideal opportunity to have a debriefing session with the athletes. However, it proved difficult to pin down most athletes at this stage of the event, as many were taking the opportunity to leave the Olympic village. In retrospect, the importance of this task was perhaps under-estimated. It is recommended that in future all team members be strongly encouraged to undertake a more structured debriefing process before they leave the Olympic village.

\section{Phase 5 - post-Olympics}

Many of the athletes were very unclear about their postOlympic futures. This uncertainty and lack of goal-focus was presumably central to the (anecdotally) increasingly recognised phenomenon of post-Olympic depression. Again, this highlights the importance of post-event debriefing sessions. Debriefs are equally important for athletes who plan to continue competing after a major event, as their emotional and cognitive responses to the latter inevitably influence their approach to future events.

\section{General}

If no one else has taken on the task, then the psychologist(s) working with future South African Olympic teams should, as one of his/her (pre-Olympic) tasks, ensure that the South African living quarters in the Games village are both comfortable and personalised. It was apparent in Athens (both from South African athletes' comments and from observing other countries' living quarters) that little things like sun umbrellas in hot spaces, a comfortable communal lounge in which people from all the codes can interact, can do much for overall team morale.

A very strong sentiment among the athletes was that decisions which impacted either directly or indirectly on their performances, were sometimes made in ways which prioritised the decision-maker's needs above those of the athlete. This is in fact a strong theme running throughout South African sport. As support staff to the athletes, non-athlete team members (including coaching, administrative and medical staff) have a responsibility to try and understand the source of these perceptions without immediately condemning them. In other words, we need to start becoming aware not just of what decisions should be made, but also of how these might best be conveyed to the athletes (in order to have the most beneficial effect on the athlete's wellbeing and performance). In this regard, psychologists can once again add significant value by playing a greater consulting role with support staff prior to the next Olympics.
Finally, a shortcoming of this paper is that it sought feedback only from athletes and their coaching and management staff. Medical (11) and NOCSA (8) staff would have provided further useful information.

\section{Conclusion (and future recommendations)}

The programme for the psychological preparation of the Athens 2004 team was the most comprehensive programme yet employed by a multicoded South African team.

In short, this model appeared to work very well, and this author believes that if it is used again, it would provide an excellent foundation on which to improve further the psychological preparation of future South African teams.

There was an almost unanimous feeling among athletes, coaches and managers that the existing programme should be expanded and be implemented on an ongoing basis, with the next cycle starting immediately post-Olympics.

In this regard, the biggest failure of South African sport psychology lies not in the levels and areas of its expertise, but in our collective failure to convince the relevant decisionmakers to support and prioritise ongoing psychological support and development programmes. After all, mental skills are no different to technical skills in needing many years to refine. Any short-term intervention (either in response to a crisis or otherwise) is automatically limited in efficacy by its inability to reinforce its teachings over time, and throughout the different levels of that sporting code's participants.

Were such a comprehensive programme to be implemented by a sporting body, its vision should be to produce athletes who have the psychological skills to go to any event, in any context (including the high-pressure cauldron of the Olympic Games), and still be able to compete consistently to the peak of their current potential (as determined by age and experience, availability of resources, etc). In other words, regardless of external circumstances and pressures, the athlete should have the ability to perform at his/her potential.

The following is a synopsis of what needs to happen for future South African Olympic teams to get as close as possible to this ideal state of preparation:

- Start the next cycle of psychological preparation immediately post-Olympics.

- Continue the existing model of having a coordinating psychologist working with a network of service providers around the country. The coordinator should be part of the medical team to the Olympics.

- The aims of the programme should be to psychologically educate and support all potential (athlete and non-athlete) members of the South African team.

- The coordinating psychologist should do a comprehensive individual needs analysis with all relevant parties. Thereafter individuals should be (where necessary and appropriate) referred to a local service provider for intervention. 
- The coordinating psychologist should visit each major centre at least twice a year, with a view to establishing and maintaining rapport with athletes, coaches, regional psychologists and other significant parties.

- The coordinating psychologist should maintain ongoing contact between visits, e.g. by sending out educational newsletters.

- Closer to the next Olympics, the coordinating psychologist should organise a series of developmental and organisational workshops with all travelling members of the SA team (including athletes, coaches, managers, NOCSA administrative staff and medical team).

- The coordinating psychologist should ensure that the accommodation of the SA team in the Olympic village is personalised, with a view to maximising comfort, functionality and patriotic spirit.

- Assuming that this model has been effectively implemented, the role of the psychologist at the Games should officially only be one of crisis management and support.

- Ways of contacting the psychologist in the village should be made as clear and as simple as possible.

- The psychologist should have unlimited access to all training venues.

- A structure should be put in place to ensure a debriefing process for all.

\section{Acknowledgements}

With thanks to: NOCSA, Ernst \& Young, Mary Ann Dove, all the psychologists throughout South Africa who provided services, and the Pacific Institute.

\section{References}

1. Bond JW. Applied sport psychology: Philosophy, reflections and experience. International Journal of Sport Psychology 2002; 33 (1): 19-37.

2. McCann SC. Doing sport psychology at the really big show. In: Anderson, ed. Doing Sport Psychology. Champaign, IL: Human Kinetics, 2000: 20921

3. Potgieter JR. Lessons from the Olympics: Participants' perceptions of the 2000 Games. SA Journal for Research in Sport, Physical Education and Recreation 2001; 23, (1): 51-64.

4. Ravizza KH. A philosophical construct: A framework for performance enhancement. International Journal of Sport Psychology 2002; 33(1): 4-18.

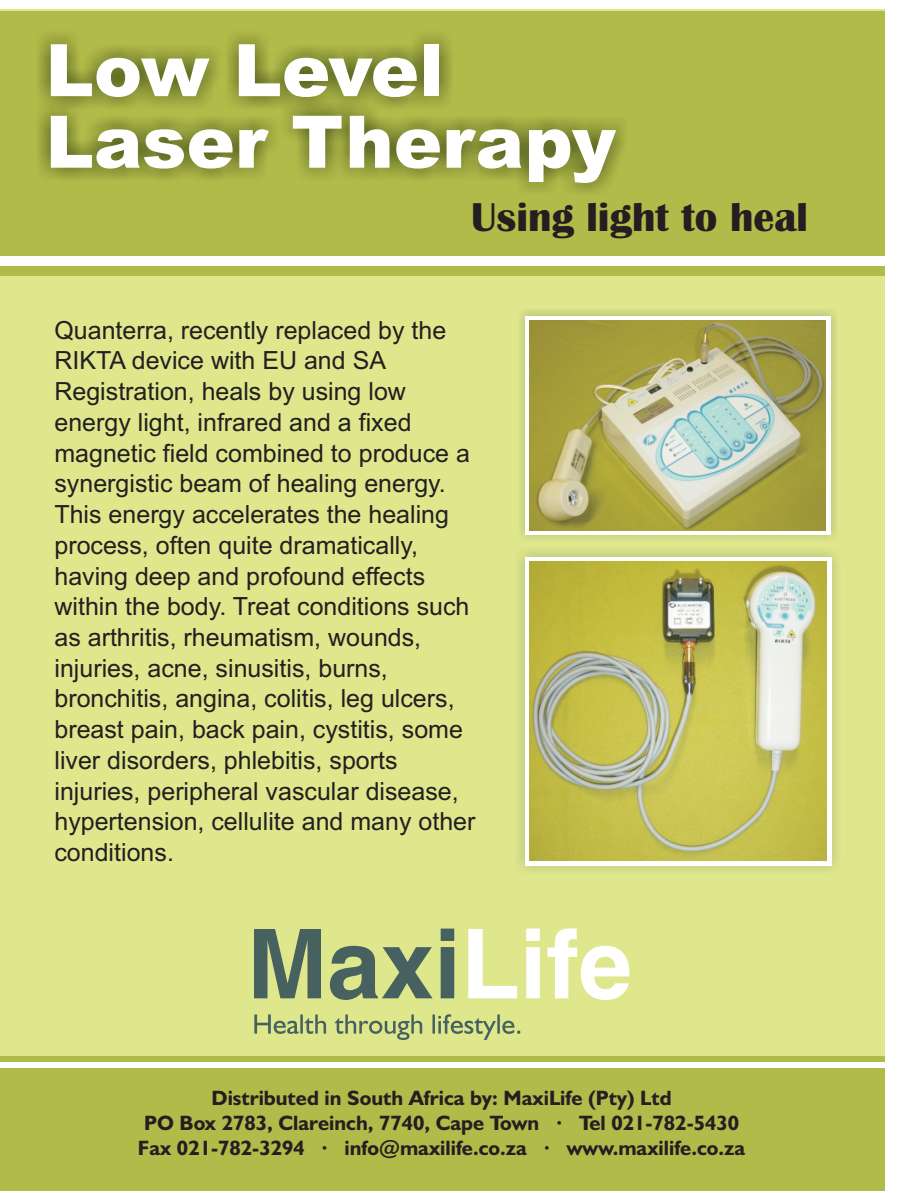

